\title{
Approaches to Identifying the Compliment Data
}

\author{
Dr. Abolaji Samuel Mustapha \\ Dept of English, Lagos State University \\ PMB 001, LASU Post Office, Ojo, Lagos, Nigeria \\ Tel 234-80-2975-6898 E-mail: abolajimustapha@hotmail.com
}

Received: June 15, 2011

Accepted: September 10, 2011

Published: February 1, 2012

doi:10.5539/ijel.v2n1p220

URL: http://dx.doi.org/10.5539/ijel.v2n1p220

This research was partly sponsored by the Commonwealth Universities Scholarship Scheme, London, between 2000-2004 at the University of Essex, Colchester, Essex, UK.

\begin{abstract}
Scholars' interest in the speech act of complimenting has grown over the years for many reasons one of which is its being robust with sociolinguistic information. However, it appears that many studies still grapple with what the compliment is because of its nature which has been described to be naturally ubiquitous and many times overlapping with other speech functions. In addition, fieldwork experiences have also called for the need to define the compliment although some scholars have argued that there is no need to define the act. In this paper, we glean from fieldwork experiences and data analysis in a study of 1200 compliments in Nigerian English to support the claim that a definition is needful and to propose some defining characteristics (termed approaches) that might be useful for those researching on the compliment data.
\end{abstract}

Keywords: Approaches, Defining, Compliments, Socio-pragmatics

\section{Introduction}

Although many researchers have studied the speech act of complimenting it appears that, generally speaking, most works give little or no attention to defining the compliment. This has not been very helpful as many similar positive statements like congratulations, praises, flatteries, and other speech functions are often confused with compliments. In fact, in spite of Holmes's (1986) observation that stressed the need to define the compliment when collecting and analyzing examples of a particular speech act, it is important to have a clear definition in order to decide what counts and what does not count as compliments, no work (to the best of my knowledge) has given due attention to defining the compliment. The reason for this neglect might be traced to the position of some scholars who argue that defining the compliment is not necessary. Their position has been anchored on some of the reasons explicated in the proceeding paragraphs.

Their first reason is based on their fieldwork experience. For example, according to these scholars, the students who were involved in the collection of their American compliments were reported to have asked nothing about describing or defining compliments, and did not indicate confusion concerning what was expected of them. The data which they collected, (going by the report) with almost no exception, were unambiguously identifiable as compliments (Manes and Wolfson, 1981, p. 127). Other studies have also reported that the ease with which compliment sets were collected.

In addition, these scholars also argue that the mobility of compliments in natural conversation makes them easy to identify. Compliments, unlike greetings are said, to be rarely tied to any fixed position within interaction: they occur at the beginning, middle and end of a conversation.

This school of thought has added that aside from the ease with which they collected their compliment data and their natural mobility in interaction, compliments are said to be independent of the utterances that precede them. Manes and Wolfson (1981) reported that:

If a compliment appears as an aside, in the middle of a conversation or, as is

frequently the case, begins the conversation, the listener may well be confused 
as to the intended object of the compliments, but whether compliments occur at

the beginning of a conversation, in isolation or during an interaction of which they are

not integral part, their independence from what precedes (them) makes it imperative

that they somehow be readily identifiable as compliments (p.125).

In other words, because compliments stand out as a distinct speech unit within interactions that feature makes them easy to identify; therefore, collectors seem to assume that they do not require any description or definition.

Finally, they have adduced from the formulaic nature of the speech act of complimenting that describing the act is uncalled for. They claim that as a formulaic speech act like greetings, apologies, thanks, and farewells, compliments make themselves readily identifiable in discourse. In fact, some studies show that restricted syntactic structure and pre-coded lexical items generally characterise the structure of compliments. For example, Wolfson (1978) show that compliments seem to be pre-coded and highly recognizable in structure, relying on only a few syntactic patterns. Wolfson and Manes (1980) found that $80 \%$ of the compliments in their corpus were adjectival compliments, and within the set, two-thirds depend on only five adjectives to carry the positive semantic load. In addition, studies have shown that certain topics are prominent as objects of praise in compliments - appearance (natural beauty, or attractiveness that result from self-effort), performance/attainment or skills, personality/character traits and possessions. Ruhi (2001) adds affect compliments although this category may be subsumed under personality compliments. Thus it has been argued that these topics of praise make compliments readily identifiable to data collectors and analysts. Herbert (1989) sums this position thus: "Compliments are, on the whole, readily extracted from discourse" (p. 5). Thus far is the claim of scholars who argue that it is not necessary to define or describe the compliment data.

On the other hand, there are scholars who have argued that there is the need to define the compliment. For example, Holmes (1986) that studied New Zealand English noted that a definition is a required tool for data collectors. Irvine (1986) also argues along the same line that analyses of speech functions such as compliments are often circular in that they do not provide information which could enable one to identify compliments unless one already intuitively know what utterances counted as compliments. Other researchers have also observed that most of the functions of compliment (Holmes, 1995; Mustapha, 2011) as offers of solidarity, as pre-acts, flatteries, greetings, rewards and congratulations very often overlap with the functions of other speech acts. Because of these overlapping functions they argue that it might be necessary for data collectors and analysts to define the compliment they are collecting and analyzing.

Compliments are not only similar to other speech acts in function but also in form. This observation has forced some studies to make a general distinction between compliments and some other speech acts such as praises, congratulations, appreciation and other positive evaluative statements (Holmes, 1988; Kerbrat-Orechioni, 1987; Lewandowska-Tomaszczyk, 1989; Maradin, 1987; Norrick, 1980 and others). For example, Holmes (1988) noted that not all positive statements and praises are compliments. Thus compliments form a subset of statements of praise and admiration, which share many things in common with others. The thin line that demarcates these statements of praise makes reliance on what has been described as popular widespread agreement on what it is that constitutes a compliment unsafe, especially for cross-cultural work. For example, some fieldwork assistants who helped in the collection of compliments for our study of compliments in Nigerian English had to be trained on what compliments are because they could not distinguished compliments from the other statements of praise. In Example 1, a fieldworker took the speaker's utterances as a compliment sets whereas only the second statement is a compliment. The difficulty that the assistant encountered was whether to classify the conversation as congratulations or a compliment or as both. However, we know that the first part is congratulations while the second part is a compliment.

\section{Example 1}

A: Congratulations! This is a very beautiful car.

B: Thank you.

Lewandowska-Tomaszsky's (1989) distinction between praises and compliments in her Polish data suggests the limitation in relying on popular agreement in identifying compliments. Her comparative study of praising and complimenting based mainly on the material from Polish with some reference to British and American English compliments highlights the differences between praises and compliments. She concludes that praising as a term has a wider range than complimenting in Poland. Therefore researchers need to make clear whether they are exploring praises or compliments. Similarly, when we compare between flatteries or insincere compliments and sincere compliments, we are not likely to find any differences in form and yet the two acts do not have the same 
function. According to Barnlund and Akari (1985) "Americans tend to draw a sharp boundary between compliments and flattery: they regard compliments as authentic expressions of admiration without manipulative intent" (p. 12). However, according to their study the same cannot be said of compliments in the Japanese language because its sanji (which means compliments) and oseji (flattery) are both expressions of praise. Though sanji "implies a more modest and subtle expressed compliments, oseji, on the other hand, might be honest or not, but could be used simply to promote conversation or more harmonious relations" (Barnlund and Akari, 1985, p. 12). For data collectors searching for compliments, when is an oseji honest praise (compliments) and when is it flattery? To avoid the confusion that these terms may cause researchers, a working definition might be necessary.

Although it has been noted that such confusion might be avoided by engaging native speakers in the data collection exercise because of their intuitive knowledge of what compliments are in their language, yet it has been argued that relying on the intuitive knowledge of native speakers on what utterances count as compliments is unsafe. While a native speaker's knowledge might assist in identifying, collecting, understanding and interpreting compliment data, unchecked reported data, anecdotes and explanations based solely on intuition are sometimes faulty and many times misleading. For example, native speakers might note down what they think speakers do rather than what they hear in the field. For example, our fieldwork assistants who are native speakers of Nigerian English could not distinguish between statements of praise (e.g., That is very good (a teacher's response to a student's answer to a question) and compliments until we trained them on what compliments are. In addition, evidence from cross-cultural studies (Herbert, 1989; Holmes and Brown, 1987; Thomas, 1983 and others) shows that compliments differ from one community to another. For example, objects of praise and the wording of compliments may differ from one community to another.

Another claim which supports the need to have a working definition is based on the fieldwork experience of some studies. Following the general characteristics of compliments given in the literature, Jacob, Aaakhus and Aldrich (1993) found that only $20 \%$ of their American compliment corpus could be categorized as compliments. They had to expand the criteria set of the common knowledge of what compliments are to accommodate the rest $80 \%$ of their corpus. Thus Aakhus and Aldrich (2002) observe that "compliments are not always bald, as the grammatical approach suggests, but can be coiffed in many ways: the inference of a compliment may not depend on issuing an explicit compliment formula" (pp. 399,400). They gave an example: "I don't know how you did that so quickly" which they claim have the force of a compliment through an inference that having accomplished something quickly is positive. Thus "compliments can be inferred from aspects of the social context that the speaker's message brings into play" (Aakhus and Aldrich, p. 400). Therefore, they argue that having, at least, a working definition should precede the study of compliments in any given community.

From the foregoing, it appears that in spite of the usefulness of native speakers' intuitive knowledge, which might be a starting point for data collection, it has been noted that their knowledge of what compliments are may not always fully match what speakers do in daily interactions. In Example 2, an uninvolved observer, a native speaker of Nigerian English and a participant during an interview might have taken the example as a compliment like the others that are said to make recipients happy. However, the act was given with the intent to correct (or mock) the recipient's immodest dressing: the dyads acknowledged this intent.

Example 2: A girl shows off her dress before her roommate and a visitor.

A: What a nice dress you have!

B: Is this nice or you're actually telling me it's bad?

A: You too knew it was bad to wear such a short skirt, try wearing something better.

B: Thank you, auntie.

This illustrates one of the shortcomings of native speakers' intuitive knowledge of what compliments are.

Similarly, as useful as the formulaic nature of compliment could be in identifying the data, especially the syntactic structures and the particular preference of certain verbs such as like, love, admire) and some adjectives such as good, nice, fine as clues that point to the distinctive features of compliments, it might be helpful to have a working definition because of the difficulty in distinguishing compliments from the other speech acts, its variation in form, its cultural differences and evidence from cross-cultural studies. And the kind of definition required should be culture-specific, and not essentially universal. In other words, it should be both emic and etic. In this case, a universal or an emic definition might be useful for researchers in general, but each research attempt targeting a given speech community will require specific (etic) definition for the speech community under investigation. In what follows, we provide some approaches to identifying the compliment data. 


\section{Approaches}

In this, we review some of the definitions in the literature which are modified in this paper based on our fieldwork experiences and analysis of 1200 compliment data collected among users of Nigerian English in Lagos. The researcher and some fieldwork assistants used field notes to collect recalled compliments from educated users of Nigerian English who had given/received compliments. Compliments that were given or received before the fieldworkers were also noted including compliments that were found in popular prose and drama texts written in Nigerian English e.g., Achebe's Things fall apart, Alkali's The Stillborn and Rotimi's The gods are not to blame. The researcher also interviewed some of the subjects on what compliments are and their functions in their speech community.

\subsection{The functional approach}

The functional approach to identifying the compliment data appears to be the most popular among researchers. It spells out what compliments primarily do without any claim to the other aspects of the compliment such as their grammatical structures and form. A classic and widely quoted definition of the compliment is that of Holmes (1986) which says that "a compliment is a speech act which explicitly or implicitly attributes credit to someone other than the speaker, usually the person addressed, for some 'good' (possessions, characteristics, skills, etc) which is positively valued by the speaker and the hearer" (p. 485). This definition underlines two major concepts - first, that a compliment is a speech act - an expression that performs an act (offers verbal gifts and attributes credit to the recipient thus making the addressee feel good) and second, it introduces the place of cultural acceptability of the topics of praise to both interactants. In sum, the speech act of complimenting meets the positive face needs of the addressee and also accomplishes certain functions that are culture-specific.

This is in consonance with Austin's theory of speech act which argues that the uttering of the sentence is, or part of, doing an action aside from the sense or reference that it makes. In other words, in saying a sentence, the speaker performs the locutionary act of vocalizing the sentence with a certain sense and reference, and also of necessity, performs an illocutionary speech act. In addition, these acts normally have effects on the feelings, thoughts, or action of the addressee. These he called perlocutionary acts. In this case, a compliment might be thought of as a sentence that is said or written with its own sense and reference of evaluation and admiration, which at the same time offers a verbal gift (of praise or friendship) and leaves an effect on others (e.g., makes the addressee feels good). But does the compliment fit into Austin's theory of speech acts?

Austin (1962) described sentences that give perlocutionary effects performatives ("declarative statements that do an action") distinguishing them from constatives (declarative statements whose truth or falsity can be judged). The performative verb "that realizes a particular action (the action that the verb 'names') when uttered in a specific context is integral as in Example 3.

Example 3: I do take this woman to be my lawful wedded wife.

(As uttered in the course of marriage ceremony (performative)).

Although compliments (e.g., I like/love/admire your skirt) lack such performative verbs Aakhus and Aldrich (2002) argue that "compliments are not excluded from speech acts: they are indirect speech acts, in that they perform through other speech acts, such as assertions" (p. 401). In fact, some compliments fit into constatives (e.g., Your skirt is nice/You look nice) because, the truth/falsity they assert can be judged. Also Austin's distinction between performative and constative can be collapsed into one - utterances that have the same qualities (truth/falsity and felicitous/infelicitous). What this means is that both constatives and performatives involve judgements of truth and falsity on the one hand, and of felicity and infelicity on the other hand (Schiffrin, 1998, p. 54). It is noted that unlike promises or requests that have explicit performative verbs (e.g., I promise to send the draft), compliments lack such action words although Example 4 is a possibility.

Example 4: I compliment you on your nice tie.

Although illocutionary analysis has not been applied to the speech act of complimentiong using Austin's theory of speech acts because compliments lack performative verbs as we have in promises and requests, Searlean felicity conditions (which were developed from Austin's concept of felicity) have been applied on compliments to show their illocutionary force. Jacobs et al (1993) and McLaughlin (1984) used illocutionary analysis (concept of felicity conditions) to define the conditions under which a message is understood to perform a certain act (when an utterance counts as a compliment). Jacob et al (1993) provide four felicity conditions for compliments which are (i) propositional condition (the speaker must indicate a positive value for an attribute, state, or event), (ii) sincerity condition (the speaker must approve of the attribute, state or event being mentioned),(iii) preparatory conditions (the attribute must have positive value; the attribute must be noteworthy and the hearer 
must be able to take credit for the attribute; and (iv) essential conditions (the utterance has to count as recognition and approval of the attribute, state, or event credited to the hearer). As useful as this illocutionary analysis is, it must be noted that it does not accommodate utterances that are ambiguous in their design (Aakhus and Aldrich, 2002, p. 401). However, the illocutionary approach provides nearly sufficient conditions whereby compliments can be analyzed and classified as speech acts.

If compliments are speech acts, we are confronted with the problem of identifying units within the acts that are not necessarily speech acts. In other words, shall we refer to the first pair of the compliment exchange or the two units of the exchange - compliment and response as in Example 5 as the speech act of complimenting? One of the ways to resolve this difficulty is by expatiating on the concepts of speech acts, speech event and speech situation. Hymes (1972) argued that while the speech event is restricted to rule/norm governed activities or aspects of activities of speech purposes, a speech event may consist of a single speech act, but often comprises several. Generally, magnitude marks the difference between a speech act and a speech event. For example, a party exemplifies a speech situation, a conversation during the party, a speech event, and a joke within the conversation, a speech act. Hymes described the speech act as the minimal unit representing a level distinct from the sentence and not identifiable with any portion of other levels of grammar, not with segment of any particular size defined in terms of other levels of grammar.

However Hyme's definition might be problematic using Example 5 which is a real life exchange. While the utterances in lines (i), (ii) and (iiia) contain greetings, utterances (iiib), (iv) and (v) introduce the topic of conversation; utterance( vi) proffers a compliment and the first of (vii) responds to the compliment, the second part is a means of leave-taking. In this case, the compliment as a unit is woven into the speech situation. Hymes (1972) realized the complexity of his description and noted that a speech event may consist of a single speech act just as an occurrence of a noun may at the same time be the whole of a noun phrase and the whole of a sentence e.g., "Fire". Therefore, a speech act may be the whole of a speech event.

Example 5: Two graduate students meet along the staircase on their campus

Hen: Good morning o, and how are my people? i

Sam: They are fine. And you? ii

Hen: I'm fine. These are the sandals (pointing to her feet) I was talking about. Iii

Sam: Ahhhhh, they are quite feminine. iv

Hen: I told you... v

Sam: But they are nice. vi

Hen: (pauses) oookay, thank you (in a very low tone smiling) Let me go bye, bye.

Sam: Bye.

In fact, there are occasions when a compliment would form the subject of a conversation although very often compliments occur within other conversations, as in Example 5.

Considering the description of the speech act as the minimal term that represents a level distinct from the sentence, the compliment and the response may be taken as a speech act. In other words, a compliment and its response should be taken as a whole unit. On the other hand, if either of the two (the compliment and the response) is being looked into, it is still a speech act because each sub-unit performs an act although a detailed study of compliments requires a record of the entire speech event. In this sense, the term speech event would be more appropriate for the researcher (who is in the field collecting data or analysts analysing compliments.

Thus the functional or illocutionary approach to identifying the compliment data sets out rules for inferring utterances that count and those that do not count as compliments. This means that sentences that are direct compliments (e.g., I like your hairstyle) and indirect compliments (e.g., I am glad I went to the same school with cool-headed people like you) are easily identified as compliments once they satisfy the four types of felicity conditions. In addition, it must be mentioned in passing that functional definition of the compliment advocates for the exclusion of praises and positive assessment from the pool of acts to be classified as compliments. Holmes (1986) state categorically that positive evaluation will not count as compliments. Exchanges such as we have in Example 6 are not compliments because the possessors of the attribute praised are not being praised directly, nor are they related to the addressees. In other words, since they do not satisfy the preparatory condition (the hearer must be able to take credit for the attribute) they are not compliments.

Example 6: Two elderly women discussing a new TV newsreader 
A: Oh but you must admit she's got a lovely voice.

B: She certainly has.

The point is that where the person whose attributes are being praised is absent at the speech context and is not related to the addressee in any way, the positive statements as in Example 6 are not compliments.

However, it might be problematic to detach compliments from praises and positive evaluation/judgment. In fact, the linguistic form bearing the semantic load of the compliment might be tagged praises or positive evaluative statements although distinguishing between compliments and positive statements may not be difficult. For example, Polish speakers who take praises as a broader term for compliments may not have any difficulty distinguishing between them. Praises such as 'Joan is polite' said in her absence might be different from uttering the same statement before her mother who takes the credit for good upbringing of her daughter since the daughter is related to her as the mother. In the case of a relation to the addressee that might be used to distinguish praises from compliments, it is argued that compliments can always construct a relationship between the addressee who is related to the person praised (the latter may not be present at the speech context) thereby making the intention as what counts to give a compliment. However, it appears that intention alone does not solve the problem because it is only one of the conditions.

In sum, what the functional or illocutionary approach proposes is the meeting of all the types of felicity conditions as analyzed by Jacobs et. al (1993) since what compliments perform - their illocutionary force is one of the standard approaches to identifying compliments in the literature.

\subsection{The folk belief approach}

The folk belief approach to identifying the compliment data underlines spontaneity. This position is based on the description of the compliment that says that sincere compliments are spontaneous while insincere ones are premeditated. For instance, Herbert (1991) observed that "Poles, like English speakers, assert that compliments should be spontaneous and sincere expressions of admiration although both groups admit that in certain circumstances a speaker might be obliged to offer a compliment" (p. 386). It might be admitted that very often compliments are spontaneous but also premeditated compliments like 'fished-for' compliments and those borne out of obligation are also compliments. During our interview exercise, (when we questioned the sincerity of our subjects' compliments) our respondents attributed some of their compliments to social obligation and the need to avoid causing offence to their addressees. A female interviewee was crossed with her lover who had failed to compliment her on her dressing. Eventually the lover complimented her with the compliment in Example 7.

Example 7: You are looking nice.

On the issue of sincerity, it might be very difficult to prove that non-spontaneous compliments are insincere and therefore they are not compliments. It is even more difficult to empirically prove sincerity on the basis of spontaneity. Perhaps one of the ways to resolve the thorny issue of sincerity is to apply the felicity conditions, that is, if both spontaneous and non-spontaneous compliments satisfy felicity conditions, they might be taken as compliments.

One definition in the literature which exemplifies the folk belief approach is that of Barnlund et al. (1985) which defines the compliment as any expression of positive evaluation concerning the qualities or behaviour of another person without manipulative intent. This definition stresses good intentions although good intentions are very difficult to determine by looking at the form of the compliment alone because compliments sometimes function as pre-acts or gambits that are geared towards certain goals aside from meeting the positive face needs of the addressees. For example in Example 8, the dyad shares the meaning of 'am interested', which the compliment helps to introduce. This manipulative intention, which the speaker verbalizes by using the compliment as pre-act does not disqualify the utterance from being a compliment.

Example 8: A man meets a woman along the road and they exchange greetings.

A: You are looking sweet today and I am interested.

B: Thank you, but am not.

However, one advantage of the folk belief approach is that it stresses the importance of self-reported data. For example, self-reported data from dyads who believe that the compliments they gave or received are sincere should suffice and be more reliable than those got from non-involved participant that may lack such details. However, observed compliments may be taken as sincere compliments if they satisfy the other felicity criteria. 


\subsection{The prototypical approach}

The prototypical approach proposes a formulaic illocutionary component for compliments and also provides pragmatic input. Lewandowska-Tomaszczk's (1989) attempted to account for compliment exchanges among some young Polish adults and proposed a formula that provides prototypical cases for the act of complimenting. Her formula contains the following set of illocutionary components:

\section{Formula I}

\section{Lewandowska-Tomaszczk's Components of Complimenting}

(a) there is a property a related to $\mathrm{A}(\mathrm{ddressee})$,

(b) $\mathrm{S}$ (speaker) acts as if $\mathrm{s} / \mathrm{he}$ evaluates a positively;

(c) $\mathrm{S}$ expresses his/her appreciation verbally directly to $\mathrm{A}$ in speech using formulaic semantic-structural patterns and

(d) teleologically to make A feel good in order to establish or maintain solidarity with A, optionally to ensure profit from $\mathrm{A}$.

In Formula II, Lewnadoska-Tomaszczk proposes other types of positive assessment utterances.

Formula II

\section{Lewandowska-Tomaszczk's Components of Responding to Compliments}

(a) there is a property a related or unrelated to A;

(b) S evaluates a positively;

(c) S expresses appreciation verbally employing any of the options and

(d) for referential and/or informative reasons, possibly to stimulate A to maintain the property a, or to stimulate $\mathrm{x}$ to follow A with respect to property a.

In Formula II where there are four components, there is an actual change of the addressee in (d). The teleological options mentioned are taken as if a is related to A(ddressee) (Lewandowska-Tomaszczyk, 1989, p. 80).

Formula I applies to the compliment and this is very useful especially when identifying compliments in both verbal and written texts. It also points at the cognitive processes that speakers go through in the complimenting act. However, it appears that the speaker (complimenter) is given such prominence that we are left with an impression that the receiver (complimentee) is the passive, non-responsive possessor of attributes who must be made to feel good. Thus her prototypical approach is complimenter-centred although we know that complimenting is a two-way act involving both the giver and the receiver. In fact, Herbert's (1989) description (though not of the prototypical approach) captures the compliment as a speech event where (i) A(ddressor compliments B and (ii) B (complimentee) acknowledges that A has spoken. In this case, we have a complete speech event that has the two components - complimenting and responding. Thus the cognitive process and the utterance of the speaker are parts, not the whole consequently emphasizing the need to account for the place of the receiver who must acknowledge the utterance as a compliment and respond in a way to show acceptance or rejection, in other words, to affirm, reject, minimize the praise, or choose not to respond verbally (smiling).

One other suggestion that might help improve on the formula is that the prototypical approach which stresses speaker's evaluation should also account for social input. Society recommends and regulates what individuals do (although there is room for transgressing and innovating social norms), to a certain extent. In other words, the speaker sees/notices what society values and then expresses approval as a representative of the community. These suggested improvements have been built into our proposed Formula III which describes the complimenter's components first and the recipient's component in Formula IIIa and Formula IIIb, respectively.

Formula IIIa

Addressor's compliment

(a) The speaker's mental process - Speaker A sees, thinks, feels, experiences in addressee or in someone related to the addressee; Addressee's attributes - his/her appearance, performance, possessions, taste, personality, skill, etc

(b) Intention - and is obliged or compelled by a sense of politeness or social practice to create, start, reinforce solidarity, and for other motives; 
(c) Acts/locution - to utter or write a compliment.

Formula IIIb

Addressee's response

(a) The Addressee's mental process - addressee interprets the compliment, considers the relationships, shared beliefs and others;

(b) Acts/locution - and responds in verbal and/or non-verbal acts.

\subsection{The formal approach}

The formal approach stresses the linguistic form of the compliment and addresses the syntactic structure, semantic import, objects of praise and the position of the compliment within conversation. One of the definitions that capture the formal approach is that of Knapp, Hopper and Robert (1984) which defines compliments as utterances that are typically self-contained units that are identifiable part from the conversational context. The basis of this approach is that a few grammatical patterns describe such a large percentage of naturally occurring compliments in most studies on compliments. This is taken as the evidence that compliments are easily recognized because there is a specific assembly of semantic and syntactic features associated with the compliment (Aakhus and Aldrich, 2002, p. 398). Knapp et al argue that a compliment is best characterised as: (i) an uncomplicated linguistic unit with a subject-object structure; (ii) which expresses an evaluation directly to another person about his/her attributes, behaviour, and possession and (ii) which is not normally perceived as occurring during final states of a conversation. This description exemplifies the formal approach.

Another description of the compliment which exemplifies the formal approach is that of Aakhus and Aldrich (2000) which agrees with what other researchers have proposed in their studies (Holmes, 1986; Knapp et al, 1984; Manes and Wolfson, 1981; Sims, 1989; and Wolfson and Manes, 1981). These studies show that a few syntactic formulas characterise the majority of the compliments they studied. To them, compliments are formulaic in structure, participatory in nature thereby spelling their form and place within conversation. Interpreting these characteristics, Wolfson (1981) mentioned that "they have the function of making compliments readily identifiable across social groups whose speech patterns may differ in many other respects" (p. 20).

In addition, the linguistic form of the compliment also lends it to being classified into types (Knapp et al 1984 and Holmes, 1995). Holmes (1995) identified two types - direct and indirect compliments. Direct compliments usually focus on something directly attributable to the person addressed whereas indirect compliments may require inferencing based on knowledge of the cultural values of the community. The indirect attribution of credit to the addressee for good parenting in Example 9 is unambiguous only in context.

Example 9: Rhoda is visiting an old school friend, Carol and comments on one of Carol's children

Rhoda: What a polite child!

Carol: Thank you. We do our best

(Source: Holmes, 1995, p. 117)

On the other hand Knapp et al (1984) identified compliment types that are concerned with the form and the source of the compliments. They identified direct and indirect compliments, specific and general compliments, comparison and non-comparison compliments and normal comparison/non-normal comparison compliments. Indirect compliments do not actually state the value of the person or act praised (e.g., I'd hate to lose you) which may imply you are invaluable to me. Whereas direct compliments state the act praised e.g., I love your shirt. Other indirect compliments relating to sources do not state a direct speaker/receiver relationship e.g., Professor Keller said you do really nice work rather than I think you do really nice work (Knapp et al). Compliments that identify particular items or behaviour are specific e.g., You look nice in that tie is specific whereas you look nice is not. Comparative compliments compare the object or behaviour discussed with another object or behaviour e.g., You look so young is not a direct comparison but may be in context. Nevertheless, You look years younger than your little brother is direct comparison.

However, the formal approach has its shortcomings. For example, not all compliments are formulaic in pattern; in fact, some compliments may not fit into the traditional subject-verb-object structure. Some compliments are so complex in structure that they cannot fit into the traditional structure. For example, Example 10 is very lengthy and Example 11 is a rhetorical question. In fact, some compliments are couched in proverbial phrases that have complex structures. 
Example 10: The child of his mother!

Example 11: We still have men who can bend and sweep the floor?

Thus it has been argued that one problem with the formal approach is that its explanation addresses only seemingly obvious compliment forms (Aakhus and Aldrich, 2002). Jacobs et al (1993) applied the general features of the formal definition of the compliment to compile a compliment corpus and found that only $20 \%$ of the corpus could be categorized as compliments. They had to relax the formula to accommodate other compliments. Consequently, a formal approach to identifying the compliment data may be very restrictive although most studies show that many compliments use restricted codes. However, restricted code criteria should not be used to disqualify compliments that do not fit into the set formulae. Based on her study of compliments among middle class speakers of American English, Wolfson (1989) cautioned that "the pattern described, like all other sociolinguistic patterns, must be expected to vary across speech communities thus we should not expect the specific formulas or frequencies with which various types are used by speakers of American English to be matched precisely by, for example, British English speakers" (p. 119). Importantly, she noted that what counts as a compliment will differ from society to society, making interpretation of speakers' intention extremely difficult at times. And where societies have rather similar value systems, differences will occur, and it is here that the most serious misunderstanding is likely to be found among cross-cultural speakers.

\section{Summary}

From the foregoing, it appears that the adoption of approaches (an eclectic approach) would be of immense usefulness since each approach has its strengths and weaknesses. In other words, an all-inclusive definition might be near impossible because of the idiosyncratic features of the compliment data. For example, a long definition which says that a compliment is an expression by a speaker or writer to another person that

positively evaluates the addressee's or another person who is related to the addressee in one way or the other about his/her performance, appearance, personality and possession and the expression is intended by the speaker and perceived by the addressee as a positive and rewarding utterance meant to please the addressee and is unacknowledged or acknowledged in any of the available conventional forms might be very problematic although it accommodates many features such as the two-way structure, the place of the addressor as the agent and the addressee as the patient. However, it leaves out the cultural values of community and raises the controversial issue of intention.

Perhaps what might be added to the approaches suggested above are some other characteristics of compliments. One, compliments are primarily spoken and involve at least, a human speaker (agent) and a recipient (patient) in a direct interaction. Of course, written compliments have some similarities to the spoken, especially as the former is the evocative of the latter. Two, although certain objects of praise have been identified within the formal approach, there are some general compliments that do not identify specific qualities in the addressee e.g., It will be hard to miss you/I'd hate to lose you, although the context may provide the clue to the object(s) of praise.

\section{Conclusion}

Two submissions are made from what has been discussed thus far in this paper. One, compliments are not be as simple and easy to identify as some researchers would have us believe because they are rather more complex in nature thus, there is the need to have a working definition when collecting or analyzing the compliment data. Such definition should take into consideration the culture of the community concerned since compliments are culture specific in terms of what is termed a compliment and what can be praised although a general definition might be a starting point. Two, in adopting approaches to identifying the compliment data, we recommend the use of more than one approach except where the researcher wishes to narrow its data to a particular approach for certain idiosyncratic reasons. It is anticipated that these submissions would help in some ways to clarify what compliments are and how to identify them either for data collection or data analysis.

\section{References}

Aakhus, A and Aldrich, A. (2002). Crafting communication activity: Understanding felicity in "I wish I ... compliments. Research on Language and Social Interactions, 35(4), 395-425. http://dx.doi.org/10.1207/S15327973RLSI3504_1

Achebe, C. (1958). Things fall apart. Ibadan: Heinemann.

Alkali, Z. (1986). The stillborn. Ibadan: Heinemann. 
Barnlund, D. C. and Akari, S. (1985). Intercultural encounters: The management of compliments. Journal of Cross-cultural Psychology, 16(1), 9-26. http://dx.doi.org/10.1177/0022002185016001002

Brown, P. and Levinson, S. (1987). Politeness: Some universals in language usage. Cambridge: Cambridge University Press.

Henderson, A. (1996). Compliments, compliment responses, and politeness in an African-American community. In J Arnold, B. Blade, S. Davidson, S. Schewenter, \& J. Solomon, (Eds.), Sociolinguistic Variation: Data, Theory, and Analysis: Selected Papers from NWAV at Stanford Centre for Study of Language and Information (pp. 195-208). Stanford.

Herbert, R. (1989). The ethnography of English compliment and compliment responses: A contrastive sketch. In W. Oleksy, (Ed.), Contrastive pragmatics (pp. 3-35). Amsterdam: John Benjamins.

Herbert, R. (1991). The sociology of compliment work: An ethnocontrastive study of Polish and English compliments. Multilingua, 10, 381 - 402. http://dx.doi.org/10.1515/mult.1991.10.4.381

Holmes, J. (1986). Compliments and compliment responses in New Zealand English. Anthropological Linguistics, 28, $485-508$.

Holmes, J. and Brown P. (1987). Teachers and students learning about compliments. TESOL Quarterly, 523-546. http://dx.doi.org/10.2307/3586501

Holmes, J. (1988). Paying compliments: A sex preferential politeness strategy. Journal of Pragmatics, 12, 445 465. http://dx.doi.org/10.1016/0378-2166(88)90005-7

Holmes, J. (1995). Women, men and politeness. London and New York: Longman.

Hymes, D. (1972). Models of the interaction of language and social life. In J. Gumperz and D. Hymes (Eds.), Directions in sociolinguistics.(pp. 35-71). New York: Holt, Rinehart and Winston.

Irvine, J. (1986). Review of F. Coulma (ed.) Conversation Rountine. Language in Society, 15, 241-245.

Jacob, S., Aakhus, M and Aldrich, A. (1993). This is a really great paper: How to recognise a compliment. Paper presented at the Annual Convention of the International Communicaqtion Association, Washington, DC.

Johnson, D.M. (1992). Compliments and politeness in peer-review texts. Applied Linguistics, 13/1, 51-71. http://dx.doi.org/10.1093/applin/13.1.51

Johnson, M. D. and Roen, D. H. (1992). Complimenting and involvement in peer-reviews: Gender variation. Language in Society, 21, 27 -57. http://dx.doi.org/10.1017/S0047404500015025

Kerbrat-Orecchio, N. C. (1987). La description des exchanges en analyze in Versation elle L'example du compliment. DRLAV-Revue de Linguistique, 36(37), 1- 53.

Knapp, L., Hopper, R. And Robert, A. (1984). Compliments: A descriptive taxonomy. Journal of Communication, 34(4), 12 - 31. http://dx.doi.org/10.1111/j.1460-2466.1984.tb02185.x

Lewandowska-Tomaszczyk, B. (1989). Praising and complimenting. In W. Oleksy, (Ed.), Contrastive Pragmatics (pp. 73-100). Amsterdam: John Benjamin.

Manes, J. \& Wolfson, N. (1981). The compliment formula. In F. Coulmas (Ed.), Conversational Routine. Berlin: Mouton.

Marandin, J. (1987). Des mots et des actions: Compliments, compliment et l'action de complimenter. Lexique, 5, 6-99.

McLaughlin, M.L. (1984). Conversation: How talk is recognized. Beverly Hills, CA:Sage.

Mustapha, A. (2011) Some functions of Nigerian English compliments. In O. Okoro, (Ed.), Nigerian English in sociolinguistic perspectives: Linguistic and literary paradigms (pp. 98 - 108). Saarbrucken: VDM Verlag Dr. Muller GmbH \& Co. KG.

Norrick, N.R. (1980). The speech act of complimenting. In. E. Hovdhaugen (Ed.), The Nordic Language and Modern Linguistics. (pp. 296-304). Oslo: Universitetsforlaget.

Rotimi, O. (1975). The gods are not to blame. Ibadan: Oxford University Press.

Ruhi, S. (2001). Complimenting women in Turkish:Shaping identities and defining ingroupness. In E.Nemeth (Ed.), Pragmatics 2000 (pp. 480-495). AntwerpP: IprA.

Schiffrin, D. (1998). Approaches to discourse. Cambridge ,Mass :Blackwell. 
Seale, J.R. (1975). Indirect speech acts. In P. Cole, \& J. L. Morgans (Eds.), Snytax and Semantics, Speech acts (pp. 59-82). New York: Academics.

Seale, J.L. (1969). Speech Act. Cambridge: Cambridge University Press.

Sims, A. (1989). The compliment sequence. Southern Communication Journal, 54, 171-184. http://dx.doi.org/10.1080/10417948909372754

Thomas, J. (1983). Cross-cultural pragmatic failure. Applied Linguistics, 4(2), 91-112. http://dx.doi.org/10.1093/applin/4.2.91

Wolfson, N. (1981). Invitations, compliments and the competence of the native speaker. International Journal of Psycholinguistics, 24(4), 7-22.

Wolfson, N. (1983). An empirically based analysis of complimenting in American English. In N. Wolson \& E. Judd (Eds.,) Sociolinguistics and language acquisition (pp. 82-95). Rowley, Mass: Newbury House.

Wolfson, N. (1989). Perspectives: Sociolinguistics and TESOL. Boston: Heinle and Heinle.

Wolfson, N. \& Manes, J. (1980). The compliment as a social strategy. Papers in Linguistics, 13, 391-410. http://dx.doi.org/10.1080/08351818009370503 